\title{
Development of the information modeling (BIM) conceptusing Big Data technologies for the implementation of the life cycle management system for capital construction of transport infrastructure
}

\author{
Maxim Zheleznov* \\ Moscow State University of Civil Engineering (MGSU) National Research University, 129337, \\ Moscow, Russia
}

\begin{abstract}
The development of a scientific concept of information modeling in the tasks of managing the capital construction objects' life cycle is the key to the successful transition of Russian Railways Holding to digital methods of managing and controlling transport infrastructure. The result of the presented complex project implementation will be the scientific basis for the life cycle information modeling concept and information modeling methodology implementation at its stages. Taking into account the rapid increase in the volume of construction information, the development of automatic systems for collecting, processing and storing information, it is proposed to apply Big Data technologies. The project results are planned to be used as a basis for the pilot information modeling technologies' development at the stages of the railway infrastructure construction objects' life cycle.
\end{abstract}

\section{Introduction}

The project is focused on the creation of scientific and methodological foundations for solving information modeling problems at the stages of the life cycle of a railway infrastructure construction facility. Implementation of the capital construction object life cycle concept using information modeling is a key and priority task for the economy of the Russian Federation (order of the President of the Russian Federation of July 19, 2018 No.PR-1235 on the transition to a capital construction life cycle management system).

Within the framework of the project, it is planned to analyze the existing technological processes of transport construction, the regulatory and methodological base. On the system analysis basis carried out, to develop a scientific concept of information modeling in the construction of railway infrastructure facilities at the stages of the life cycle. To link the information modeling processes into a single information system, scientific and methodological foundations for data management in information modeling of railway infrastructure facilities at the stages of the life cycle will be developed, including the

\footnotetext{
${ }^{*}$ Corresponding author: zheleznovmm@mgsu.ru
} 
prospective requirements development for the classification systems for construction information and levels of digital models' elaboration (detailing). Building an integrated (continuous) lifecycle management system for a capital construction facility requires a special approach to the task of ensuring internal and external interoperability with corporate information systems of the Russian Railways Holding and external, including state information platforms. It is proposed to explore the possibilities of intelligent information processing methods, technologies and methods for analyzing Big Data, to ensure prompt information processing and ensure the interoperability of tasks in information modeling at the stages of the capital construction objects' life cycle. Further, it is planned to develop the information modeling methodologies (in fact, a description of pilot technologies) at each stage of a railway infrastructure construction object life cycle (pre-design studies and investment feasibility studies, design, construction, operation, demolition / dismantling and disposal), including the development of new methods of collection and integration of digital information into an information model using Big Data technologies and the economic efficiency of further implementation of the developed solutions.

\section{Methods}

\subsection{Research directions}

The goal of the project is to develop a scientific concept of information modeling (BIM) using Big Data technologies for the implementation of a lifecycle management system for capital construction of transport infrastructure.

Project objectives:

1. Development of the concept of information modeling in the construction of railway infrastructure facilities at the stages of the life cycle;

2. Development of scientific and methodological foundations for data management in information modeling of railway infrastructure facilities at the life cycle stages;

3. Development of scientific and methodological foundations for ensuring data interoperability in information modeling of railway infrastructure objects at the life cycle stages;

4. Development of information modeling methodology at the stage of pre-design studies and justification of investments in railway infrastructure construction;

5. Development of information modeling methodology at the design stage of railway infrastructure construction objects;

6. Development of information modeling methodology at the stage of railway infrastructure facilities' construction;

7. Development of information modeling methodology at the stage of railway infrastructure facilities' operation;

8. Development of information modeling methodology at the stage of demolition and utilization of railway infrastructure facilities.

\subsection{Project roadmap}

The project is planned to be implemented in stages, in accordance with the set goals and objectives.

Stage 1. Development of a scientific concept of information modeling in the railway infrastructure facilities' construction, including the following main sections:

1.1. Systems engineering for the creation and development of information modeling technologies in transport construction; 
1.2. Information modeling at different stages of the railway infrastructure capital construction object life cycle;

1.3. System for organizing the process of information modeling and management of construction projects using information modeling;

1.4. Prospective trends in the development of information modeling in the construction of railway infrastructure facilities.

Stage 2. Development of scientific and methodological foundations for data management in information modeling of railway infrastructure facilities at the stages of the life cycle, including:

2.1. Analysis of International Standards for Building Information Modeling;

2.2. Analysis of National Standards for Building Information Modeling;

2.3. Development of a functional model for the implementation of the concept "Open BIM" for transport construction tasks;

2.4. Development of principles for the classification of construction information for the tasks of transport construction and the recommended levels of a railway infrastructure object information model elements' elaboration.

Stage 3. Development of scientific and methodological foundations for ensuring data interoperability in information modeling of railway infrastructure objects at the stages of the life cycle, including:

3.1. Development of scientific recommendations for the implementation of a shared data environment in information modeling in construction and the applied data formats;

3.2. Development of scientific foundations to ensure data interoperability in information modeling tasks Data exchange formats;

3.3. Development of theoretical foundations for the systems analysis of data in information modeling;

3.4. Analysis of intelligent computing technologies in information modeling at the stages of the capital construction objects' life cycle;

3.5. Analysis of technologies and methods for analyzing Big Data in information modeling at the stages of the life cycle of capital construction objects.

Stage 4. Development of a methodology for information modeling at the stage of predesign studies and justification of investments in construction objects of railway infrastructure, including:

4.1. Development of the new methods' theoretical foundations for conducting pre-design surveys using information modeling technologies;

4.2. Development and scientific substantiation of the requirements for the information model at the stage of pre-design research and investment justification;

4.3. Formalization of the information modeling technological foundations at the stage of pre-project research and investment justification;

4.4. Development of new methods for collecting and integrating digital information into an information model at the stage of pre-design research using Big Data technologies.

Stage 5. Development of information modeling methodology at the design stage of railway infrastructure construction facilities, including:

5.1. Development of the new methods' theoretical foundations for the design of building objects using information modeling technologies;

5.2. Development and scientific justification of the requirements for the information model at the design stage;

5.3. Formalization of the information modeling technological foundations at the design stage;

5.4. Development of new methods for collecting and integrating digital information into an information model at the design stage using Big Data technologies. 
Stage 6. Development of information modeling methodology at the stage of construction of railway infrastructure facilities, including:

6.1. Development of the new methods' theoretical foundations for the construction of railway infrastructure facilities using information modeling technologies;

6.2. Development and scientific justification of the requirements for the information model at the construction stage;

6.3. Formalization of the information modeling technological foundations at the construction stage;

6.4. Development of new methods for collecting and integrating digital information into an information model at the construction stage using Big Data technologies.

Stage 7. Development of information modeling methodology at the stage of railway infrastructure facilities' operation, including:

7.1. Development of theoretical foundations of new methods of operation of railway infrastructure facilities using information modeling technologies;

7.2. Development and scientific justification of the requirements for the information model at the operational stage;

7.3. Formalization of technological foundations of information modeling at the operational stage;

7.4. Development of new methods for collecting and integrating digital information into an information model at the operational stage using Big Data technologies.

Stage 8. Development of information modeling methodology at the stage of demolition and disposal of railway infrastructure facilities, including:

8.1. Development of theoretical foundations for the new methods of demolition and disposal of railway infrastructure facilities using information modeling technologies;

8.2. Development and scientific justification of the requirements for the information model at the stage of demolition and disposal;

8.3. Formalization of the information modeling technological foundations at the stage of demolition and disposal;

8.4. Development of new methods for collecting and integrating digital information into an information model at the stage of demolition and disposal using Big Data technologies.

\section{Results}

The result of this scientific project implementation will be:

- Scientific concept of information modeling in the construction of railway infrastructure facilities at the stages of the life cycle;

- Scientific and methodological foundations of data management in information modeling of railway infrastructure facilities at the stages of the life cycle;

- Scientific and methodological foundations for ensuring data interoperability in information modeling of railway infrastructure objects at the life cycle stages;

- Information modeling methodology at the stage of pre-design studies and investment feasibility studies for railway infrastructure construction;

- Information Modeling Methodology at the Design Stage of Railway Infrastructure Construction Objects;

- Information Modeling Methodology at the Construction Stage of Railway Infrastructure Facilities;

- Information modeling methodology at the stage of railway infrastructure facilities' operation;

- Information Modeling Methodology at the Stage of Demolition and Utilization of Railway Infrastructure Objects;

- Methods for collecting and integrating digital information into an information model at 
the stage of pre-design research using Big Data technologies;

- Methods for collecting and integrating digital information into an information model at the design stage using Big Data technologies;

- Methods for collecting and integrating digital information into an information model at the construction stage using Big Data technologies;

- Methods for collecting and integrating digital information into an information model at the operational stage using Big Data technologies;

- Methods for collecting and integrating digital information into an information model at the stage of demolition and utilization using Big Data technologies.

\section{Discussion and summary}

The results of the work performed (concept, scientific foundations, methodologies and methods of information modeling) are planned to be applied for the practical implementation of the Roadmap for scientific and technical support for the implementation of life cycle management systems for capital construction objects of JSC Russian Railways using information modeling technology (approved by the order of JSC Russian Railways from January 29, 2020 No.161/r) as a basis for the pilot information modeling technologies' development at the stages of the railway infrastructure construction objects' life cycle, as well as in the development of programs for professional and pre-professional training of specialists in the field of information modeling in construction ("Construction of railways", "Industrial and civil construction", pre-professional orientation schoolchildren and applicants), implemented by transport and construction universities of the Russian Federation.

The reported study was funded by RFBR, Sirius University of Science and Technology, JSC Russian Railways and Educational Fund "Talent and success", project number 20-38-51013.

\section{References}

1. M. Ryu, H.-L. Truong, M. Kannala, Journal of Big Data 8(1), 31 (2021).

2. F. Meng, Journal of Physics: Conference Series 1852(3), 032031 (2021).

3. L. Shilov, S. Evtushenko, D. Arkhipov, L. Shilova, IOP Conference Series: Materials Science and Engineering 1030(1), 012039 (2021).

4. X. Huang, Journal of Physics: Conference Series 1865(3), 032016 (2021).

5. J.P. Xing, E3S Web of Conferences 248, 03069 (2021).

6. L. Wan, Y. Bai, Advances in Intelligent Systems and Computing (AISC) 1191, 704716 (2021).

7. J. Zhu, Y. Tan, X. Wang, P. Wu, Annals of GIS 27(1), 99-109 (2021).

8. A. Ginzburg, L. Shilov, L. Shilova, Journal of Physics: Conference Series 1425(1), 012156 (2020).

9. P. Krupík, Construction 4.0 with a focus on transport construction, International Multidisciplinary Scientific GeoConference Surveying Geology and Mining Ecology Management, SGEM 2020, 127-134 (2020).

10. V. Ciotta, D. Asprone, G. Manfredi, E. Cosenza, BIG (and heterogeneous) DATA in structural engineering: New opportunities for building information modelling processes and approaches, Proceedings of the International fib Symposium on Conceptual Design of Structures 161-166 (2019). 
11. R. Zheng, J. Jiang, X. Hao, (...), F. Xiong, Y. Ren, Mathematical Problems in Engineering 5349538 (2019).

12. H. Kiavarz, M. Jadidi, A. Rajabifard, G. Sohn, International Archives of the Photogrammetry, Remote Sensing and Spatial Information Sciences - ISPRS Archives 42(4/W10), 79-82 (2018).

13. N. Mazroob Semnani, P.V. Kuper, M. Breunig, M. Al-Doori, ISPRS Annals of the Photogrammetry, Remote Sensing and Spatial Information Sciences 4(4), 133-140 (2018).

14. Y. Bosdriesz, M. Van Sinderen, M. Iacob, P. Verkroost, Enterprise Interoperability: Smart Services and Business Impact of Enterprise Interoperability 209-215 (2018).

15. A. Borrmann, J. Beetz, C. Koch, T. Liebich, S. Muhic, Building Information Modeling: Technology Foundations and Industry Practice 81-126 (2018).

16. A. Tibaut, D. Zazula, Sustainability Science 13(5), 1311-1322 (2018).

17. S.E. Nisa Lau, R. Zakaria, E. Aminudin, (...), A. Yusof, C.M.F. Hafifi Che Wahid, IOP Conference Series: Earth and Environmental Science 143(1), 012050 (2018).

18. D. Wang, J. Fan, H. Fu, B. Zhang, Complexity 9691868 (2018).

19. F. Banfi, BIM orientation: Grades of generation and information for different type of analysis and management process, International Archives of the Photogrammetry, Remote Sensing and Spatial Information Sciences, ISPRS Archives 42(2W5), 57-64 (2017). 